\title{
Zonas de influência portuárias - hinterlands: conceituação e metodologias para sua delimitação
}

\author{
Ports influence zones - hinterlands: concepts \\ and methodologies for their delimitation
}

\author{
Nélio Domingues Pizzolato \\ Luiz Felipe Scavarda \\ Rodrigo Paiva
}

\begin{abstract}
Resumo: O processo de desenvolvimento de contêineres e o desenvolvimento de redes de transporte intermodal têm provocado crescente competição no setor portuário e vêm, no mundo inteiro, interferindo nas zonas de influência dos portos (hinterlands). Essas hinterlands estão deixando de ser cativas de um determinado porto para serem de múltipla influência de dois ou mais portos. O presente trabalho apresenta um estudo cujo objetivo é caracterizar a dinâmica portuária à luz da desenvolvimento de contêineres, mapear a discussão acerca do conceito de hinterlands $e$ apresentar metodologias para sua delimitação. Essa contextualização conceitual e metodológica encontra-se ilustrada com sua aplicação ao caso do terminal de contêineres do porto de Rio Grande com apoio de Sistemas de Informação Geográfica (SIG). Como resultado, os autores concluem que a delimitação de hinterlands é essencial para auxiliar o planejamento do desenvolvimento portuário por parte de Autoridades Portuárias e Terminais Privativos num cenário de crescente competição.
\end{abstract}

Palavras-chave: Hinterland. Portos. Terminal de contêineres. Sistemas de Informação Geográfica (SIG).

\begin{abstract}
The containerization process and the development of intermodal transport networks have lead to a competitive scenario in the port sector and have modified their hinterlands all over the world. Those hinterlands are no longer captive areas of one port but competitive areas among two or more ports. The objectives of the present study are to characterize the port development due to the containerization process, to map the discussion on the concept of ports ' hinterlands, and to present methodologies for their delimitation. Using Geographical Information Systems (GIS), this conceptual and methodological context allows the application of a methodology in a case study that embraces the container terminal of the port of Rio Grande. As a result, the authors conclude that the delimitation of hinterlands, in a growing competitive scenario, is essential to assist the port planning and development by Port Authorities or by private terminals.
\end{abstract}

Keywords: Hinterland. Ports. Containerization. Geographical Information System (GIS).

\section{Introdução}

A introdução e o desenvolvimento do contêiner como meio de unitização e ganho de eficiência na movimentação de cargas acrescentou um desafio adicional para o planejamento da atividade de transporte marítimo que modificou drasticamente a operação tanto das empresas de navegação quanto dos portos (LEE; SONG; DUCRUET, 2008). Para as primeiras, a principal consequência foi a concentração da atividade do transporte marítimo nas mãos de poucas empresas, em vista da necessidade maciça de capital para investimentos em navios cada vez maiores e mais modernos, como forma de redução do custo unitário de transporte; para os segundos, os desafios passaram a ser a oferta apropriada de infraestrutura e de serviços eficientes, a baixo custo.

Adicionalmente, os portos devem implantar um planejamento estratégico de desenvolvimento, de modo a responder aos desafios de um ambiente competitivo complexo e mutante, função do atual acelerado desenvolvimento tecnológico, econômico, político e social. Igualmente, torna-se necessário o preciso conhecimento de seu mercado de atuação, os níveis de serviços exigidos por seus clientes, e as oportunidades de negócios que possam alavancar suas movimentações de cargas, assim como o adequado conhecimento das vantagens relativas dos seus

\footnotetext{
${ }^{1}$ Departamento de Engenharia Industrial, Pontifícia Universidade Católica do Rio de Janeiro, PUC-Rio, Rua Marquês de São Vicente, 225, CEP 22453-900, Rio de Janeiro - RJ, Brasil, E-mail: ndp@ puc-rio.br; lf.scavarda@ puc-rio.br; rtpaiva@ terra.com.br
} 
concorrentes diretos, de forma a antecipar ações e garantir a expansão da movimentação portuária.

Neste contexto, o objetivo deste trabalho consiste na caracterização da dinâmica portuária à luz da desenvolvimento de contêineres, no mapeamento e na discussão acerca do conceito de zona de influência, internacionalmente denominada de hinterland, e na análise de metodologias para delimitação destas hinterlands, metodologias estas ainda pouco difundidas e analisadas na literatura. O artigo incorpora ainda um estudo de caso para ilustrar a delimitação da hinterland do terminal de contêineres do porto de Rio Grande/RS com o apoio de um Sistema de Informação Geográfica (SIG).

$\mathrm{O}$ método de pesquisa relacionado à conceituação e às metodologias de delimitação de hinterlands contou inicialmente com uma revisão da bibliografia referente ao tema. As informações obtidas com esta revisão foram complementadas com a condução in loco de entrevistas não estruturadas com os diretores de duas empresas de consultoria especializadas na área de gestão portuária e de transporte de navegação de longo curso e cabotagem, sendo uma delas nacional e outra multinacional que possui participação acionária de um dos maiores armadores do mundo. Ambas as empresas desenvolveram projetos relacionados a portos no Brasil em que a questão das hinterlands foi abordada de forma estratégica. Consulta a documentos e relatórios internos das duas empresas também foram realizadas pelos pesquisadores para complementar as informações obtidas com as entrevistas. As metodologias utilizadas nestes projetos foram incorporadas nesta pesquisa. Por motivos de confidencialidade, os nomes das empresas não estão mencionados neste artigo. Já a elaboração do caso contou com uma base de dados, fornecida pelo Centro Nacional de Navegação Transatlântica (CNNT), relacionada à movimentação de contêineres nos municípios do Estado do Rio Grande do Sul e com uma base gráfica georreferenciada deste estado obtida junto ao Instituto Brasileiro de Geografia e Estatística para aplicação no programa computacional SIG. O SIG utilizado foi o ArcView versão 3.3 (ESRI, 1996).

O artigo está dividido em 6 seções, sendo esta primeira a introdutória. Na sequência, a Seção 2 examina brevemente a evolução portuária; a Seção 3 apresenta o conceito de hinterland; a Seção 4 faz um levantamento das metodologias propostas para sua determinação; a Seção 5 apresenta o estudo de caso; enquanto que a Seção 6 sintetiza as conclusões do trabalho.

\section{O desenvolvimento da atividade portuária}

A United Nations Conference on Trade and Development propõe uma classificação híbrida para os portos segundo gerações de desenvolvimento, na qual as funções, atividades, estrutura organizacional, institucional, operacional e gerencial diferem enormemente (UNITED NATIONS CONFERENCE ON TRADE AND DEVELOPMENT, 2002), classificação essa também adotada no mundo acadêmico (PETTIT; BERESFORD, 2009). De acordo com esta classificação, existem três gerações, determinadas pelo desenvolvimento das políticas e da estratégia portuária, pelas diferenças de escopo das atividades portuárias e pelo nível de expansão e de integração.

A primeira geração de portos tem como limite o ano 1960. Até então, os portos desenvolviam simplesmente atividades de interface entre os sistemas de transporte em terra e em mar. As principais atividades e investimentos desenvolvidos nos portos visavam exclusivamente a movimentação e o armazenamento de cargas.

A segunda geração de portos compreende aquelas instalações construídas entre 1960 e 1980 e se caracteriza pelo trabalho em conjunto das entidades governamentais e da autoridade portuária. As atividades desenvolvidas por esses portos foram expandidas para além das tradicionais, incorporando uma série de ações que passaram a ser realizadas no porto e em sua área de influência, como a embalagem das cargas, etiquetagem e também a distribuição física. Comparando-se à primeira, a segunda geração de portos propiciou a aproximação entre os agentes econômicos do setor, o que pode ser considerado o início do gerenciamento dos serviços portuários direcionado ao consumidor, mas sem preocupações com relacionamentos de longo prazo.

A terceira geração de portos tem início na década de 1980, com o rápido desenvolvimento do transporte de contêineres e o surgimento dos sistemas de transporte intermodais (STARR, 1994; KONINGS, 2007; LEE; SONG; DUCRUET, 2008). As atividades de produção e transporte passaram a formar uma cadeia com escopo internacional. As atividades portuárias passaram a incluir serviços logísticos e de distribuição, podendo estes ser altamente personalizados englobando soluções estendidas para a cadeia de suprimentos (PETTIT; BERESFORD, 2009), e tornaram-se importantes a proteção e segurança do meio ambiente. As autoridades portuárias passaram a focar a eficiência portuária. Nessa geração, as necessidades dos clientes passaram a ser analisadas detalhadamente e as atividades comerciais e de marketing foram bastante expandidas (VELASCO; LIMA, 1999).

É possível analisar os portos também a partir de uma microperspectiva em termos de atividades e operações desenvolvidas. Uma definição simples de um porto considera-o como uma instalação em que a transferência de cargas e de passageiros, bem como a manutenção de embarcações são garantidas. Outras definições estendem as atividades portuárias para além 
da movimentação de cargas de/para embarcações, armazenamento e elos logísticos, para incluir as atividades relacionadas a empresas que participam do comércio marítimo. São então distinguidas as funções internas e externas de um porto, sendo as primeiras divididas em serviços aos navios e em serviços às cargas, o que inclui as atividades essenciais que necessitam ser fornecidas por um porto: conservação, praticagem, engenharia civil, operações de movimentação de cargas e outros serviços. Os serviços aos navios incluem aqueles executados no lado do mar, tais como atracação e desatracação, e aqueles relacionados à interface navio/terra, como reparos e manutenção, suprimentos etc. Os serviços à carga podem ser subdivididos entre os executados na interface terra/navio, tais como a carga e descarga, e aqueles desenvolvidos inteiramente em terra, como a consolidação e desconsolidação de contêineres (BICHOU; GRAY, 2005).

\section{Hinterlands}

O conceito de hinterland é conhecido desde o início do Século XX e vem sendo discutido, tanto na literatura acadêmica quanto por profissionais do mercado, mas não há uma definição padronizada para o conceito. Entre as definições existentes na literatura, podem-se destacar as oferecidas em: Bird (1971), Takel (1976), Slack (1993), Kesic, Komadina e Cisic (1998), van Klink e Winden (1998), van Klink e van den Berg (1998), Degrassi (2001), Yap et al. (2006), Konings (2007), Tan (2007), Lee, Song e Ducruet (2008) e Rodrigue e Notteboom (2010). Ao analisar essas definições, observa-se que, devido a variados contextos histórico-tecnológicos, as definições para hinterland foram sendo aprimoradas e adaptadas. De modo geral, as definições convergem no sentido de caracterizar a zona de influência de um porto como a área de mercado do porto em terra da qual ou para a qual o porto envia e recebe cargas.

Slack (1993) vai além, caracterizando-a como uma área onde um porto vende seus serviços e interage com seus clientes e que pode ser representada como a parcela de mercado que um porto tem em relação aos demais portos que servem à mesma região geográfica. Essa visão está em linha com Rodrigue e Notteboom (2010) que definem hinterland como um grupo de localidades conectadas com o porto pelo relativo fluxo de materiais, o que, como Slack (1993), associa o porto a um polo ofertante de serviços logísticos. Essas definições procuram tratar o porto como um elo logístico dentro de um mercado competitivo, em que deve atuar de forma pró-ativa comercial e tecnologicamente para garantir seu mercado. Além disso, a hinterland pode ser vista como dinâmica e mutável, podendo ser disputada por diversos portos (ou terminais) na medida em que consigam oferecer seus serviços de maneira competitiva no mercado.
O conceito de hinterland tem sofrido críticas no mundo acadêmico, principalmente no que se refere a dois aspectos: a crescente desenvolvimento de contêineres da carga geral e o desenvolvimento de redes de transporte intermodal. McCalla (1999), Haezendonck e Notteboom (2002), Lacerda (2004) e McCalla (2008), por exemplo, argumentam que a intensificação do uso de contêineres tem ampliado a atuação geográfica da captura de carga dos portos, tornando as zonas de influência de determinado porto muito mais fluidas e dinâmicas, complicando o entendimento das definições tradicionais para hinterlands. Song (2003), Lacerda (2004) e Lee, Song e Ducruet (2008) também mencionam que a intermodalidade permite que contêineres possam percorrer distâncias cada vez maiores. Isso facilita a descentralização do acondicionamento das cargas nos contêineres, podendo este ser realizado na origem das mercadorias, nas fábricas, ou por meio de serviços especializados, longe das áreas dos portos, expandindo assim suas hinterlands. Lacerda (2004) ressalta ainda o aumento dos transbordos relacionados ao aumento do tamanho dos navios porta-contêineres, pois as empresas de navegação buscam concentrar a carga em algum porto principal de cada região $(h u b)$, a fim de obter grande quantidade de carga para o transporte nas rotas longas, em navios maiores. Quanto maiores os navios, menores os custos de transporte dos contêineres, o que significa dizer que a atividade apresenta economias de escala. Diferentes portos podem dividir a mesma hinterland, cujas fronteiras dependem agora também do desenvolvimento de corredores de transporte intermodais e não exclusivamente do mercado do porto. Isso permite a competição direta entre portos distantes uns dos outros. Adicionalmente, a competição entre os portos não se restringe ao aumento da sua área de influência tradicionalmente definida, mas também de sua função de transbordo, ou seja, atrair movimentação cuja origem ou destino não seja o próprio porto ou sua área de entorno.

Apesar das críticas, o conceito de hinterland continua crítico para o desenvolvimento portuário e para a competitividade dos portos (KONINGS, 2007; YEO et al., 2008; ROSO et al., 2009; RODRIGUE; NOTTEBOOM, 2010). A delimitação da hinterland portuária e a análise de sua natureza e extensão são passos básicos na avaliação do desenvolvimento de um porto ou terminal portuário de carga.

A definição de hinterland pela visão estática é caracterizada como uma área contínua atrás do porto. Com o desenvolvimento do conceito, foram inseridas relações funcionais entre o espaço marítimo e suas localizações funcionais fora do porto como áreas industriais e centros logísticos. Para Hayuth (1982), o conceito dinâmico de hinterland portuária torna possível identificar os fatores que influenciam a expansão ou redução da dimensão da hinterland 
portuária. A possibilidade de modificação da hinterland de um porto ao longo do tempo pressupõe a existência de variáveis que influenciam a sua delimitação. Os principais fatores nessa delimitação são:

- A natureza dos bens movimentados: carga geral, contêineres, granel, etc. (TAKEL, 1976; KESIC; KOMADINA; CISIC, 1998; DEGRASSI, 2001, YEO et al., 2008); e o volume e valor movimentado destes bens (McCalla, 1999; DEGRASSI, 2001; CAMPOS NETO; SANTOS, 2005);

- A estrutura do transporte marítimo em relação à tipologia dos navios, à organização dos armadores e à frequência de escala dos navios (van KLINK; WINDEN, 1998; McCALLA, 1999; DEGRASSI, 2001);

- A estrutura da rede de transporte em terra interligando o porto e seu mercado e, consequentemente, o custo de transporte a esta rede associado (TAKEL, 1976; SLACK, 1993; KESIC; KOMADINA; CISIC, 1998; van KLINK; WINDEN, 1998; McCALLA, 1999; HOYLE, 2000; DEGRASSI, 2001; SECRETARIA DE INFRA-ESTRUTURA DO GOVERNO DO ESTADO DA BAHIA, 2004; KONINGS, 2007; LEE; SONG; DUCRUET, 2008; YEO et al., 2008; UBOGU; ARIYO; MAMMAN, 2009);

- A influência das políticas econômicas (KESIC; KOMADINA; CISIC, 1998; DEGRASSI, 2001);

- A entrada de novos portos competidores no mercado (van KLINK; WINDEN, 1998);

- A organização trabalhista nas atividades portuárias (TAKEL, 1976; KESIC; KOMADINA; CISIC, 1998);

- A infraestrutura portuária (TAKEL, 1976; KESIC; KOMADINA; CISIC, 1998);

- A competitividade do porto em termos de tarifas adequadas relativamente a outros portos (TAKEL, 1976; KESIC; KOMADINA; CISIC, 1998);

- Causas naturais, como o clima ou fatores sazonais (DEGRASSI, 2001); e

- Fatores e eventos políticos (DEGRASSI, 2001).

\section{Metodologias para delimitação de hinterlands}

A necessidade da delimitação e análise da hinterland para permitir o correto planejamento portuário, quer por parte de suas autoridades, quer por parte dos terminais, traz à tona a questão de como devem ser definidas as zonas de influência portuárias. A presente seção apresenta diversas metodologias propostas para a delimitação de hinterlands portuárias, identificadas na literatura acadêmica e especializada e em casos de aplicações reais por empresas de consultorias no Brasil, além de discutir situações práticas em que elas foram praticadas. Essas metodologias são classificadas em dois grupos, de acordo com o objetivo a que se propõem:

- metodologias para identificação da hinterland atual ou mercado de um porto; e

- metodologias para definição da hinterland potencial de um porto.

As primeiras metodologias que visam identificar o mercado de um porto (ou terminal portuário) fazem uma análise estática do seu mercado de atuação, isto é, delimitam a sua hinterland por meio de uma "fotografia" de seu mercado atual. Essas metodologias podem ser utilizadas apenas por terminais em operação, uma vez que se torna impossível o cálculo da hinterland caso não existam dados históricos de movimentação.

As metodologias para definir o potencial de um porto visam essencialmente realizar uma análise prospectiva do mercado potencial do porto, ou seja, calculam a delimitação ideal de sua zona de influência utilizando variáveis técnicas, econômicas, políticas e sociais. Seus resultados indicam a hinterland potencial de um porto ou terminal portuário, onde a área geográfica identificada pode não ser a mesma daquela de sua atuação. Pode ainda possibilitar a verificação da hinterland potencial para um novo terminal portuário, quer seja este uma nova instalação ou uma expansão de um terminal já existente.

Os dois grupos de metodologias podem ser utilizados de maneira independente, em função dos objetivos a serem alcançados. Entretanto, o ideal é a sua utilização conjunta, de maneira que se consigam realizar comparações e análises entre as zonas de influência real e potencial de um porto. Certamente, o que a administração de um porto deve esperar é que a sua área potencial de atuação esteja efetivamente alcançada.

\subsection{Metodologias para identificação do mercado de um porto}

As metodologias para identificação do mercado de um porto, ou de sua hinterland real, fazem uma análise do seu mercado efetivo. Esses tipos de metodologia podem ser utilizados apenas por terminais em operação, uma vez que se torna impossível o cálculo da hinterland real caso não existam dados históricos de movimentação.

Uma das primeiras metodologias propostas na literatura com essa finalidade foi a de F. W. Morgan divulgada em seu trabalho intitulado The pre-war hinterlands of the German North Sea ports publicado no Transactions of the Institute of British Geographers em 1948 (DEGRASSI, 2001). Essa metodologia delimita a zona de influência de um porto a partir 
da análise da movimentação das cargas de uma determinada região geográfica de/para um determinado porto. Essa identificação estabelece a classificação dessa região tomando por base suas movimentações atuais, buscando hierarquizar os municípios segundo uma curva $A B C$ de importância da participação. Assim, as zonas identificadas podem ser de três níveis: hinterland primária (grande movimentação); hinterland secundária (média movimentação); e hinterland marginal (pequena movimentação). Cabe registrar que a literatura oferece ainda outras classificações para hinterlands além da mencionada em Degrassi (2001), podendo-se destacar as contribuições de: Kesic, Komadina e Cisic (1998), cuja classificação baseia-se em aspectos geográficos, sendo: i) zona imediata de influência, adjacente à costa; ii) zona de influência de dois ou mais portos dentro de um mesmo país; iii) áreas que podem utilizar portos de um ou mais países, o chamado transit market, e Notteboom e Rodrigue (2007), que classificam as hinterlands a partir de uma avaliação: i) macroeconômica; ii) física; e, iii) logística.

Uma segunda metodologia, proposta por McCalla (1999), consiste na análise de estatísticas de movimentação de contêineres de uma região de interesse. Esta metodologia propõe a coleta de dados constantes em manifestos de carga. A partir desses dados, o autor calcula o market share de cada porto da região analisada em relação às cidades de origem e destino em terra e também à região foreland para onde os contêineres movimentados pelos portos foram destinados ou de onde foram recebidos, o que permite plotar as regiões em um mapa, delimitando a hinterland real dos portos.

Baseado na metodologia de McCalla, um estudo de mercado foi desenvolvido por uma empresa de consultoria brasileira, especializada em estudos portuários, para determinar a zona de influência de um terminal de um operador portuário no Brasil, no Estado de Santa Catarina. Para tal, foram utilizados os dados de movimentação de contêineres e levantados os municípios de origem e destino dos contêineres movimentados, na exportação e na importação. Em seguida, foi calculada a participação do terminal portuário na movimentação dos contêineres de cada município, o que permitiu a identificação de três critérios de classificação para os municípios analisados, segundo três níveis de atividade, a saber:

- O município é zona de influência de um único porto se, no mínimo, $70 \%$ de sua carga é movimentada de/para o porto;

- O município é zona de influência de dois portos se $80 \%$ de sua carga é movimentada de/para dois portos; e
- O município é zona de influência de três portos se $90 \%$ de sua carga é movimentada de/para os três portos.

A partir da classificação dos municípios, eles foram plotados em um mapa ressaltando a hinterland do terminal, de modo a elaborar um planejamento para atração de cargas dos municípios em que há concorrência com outros portos.

Em outra pesquisa análoga, Campos Neto e Santos (2005) sugerem três metodologias para estudar a atração de cargas para o porto de Santos. O principal objetivo do trabalho foi realizar uma análise detalhada e consubstanciada dos principais produtos movimentados pelo porto e delimitar a área de influência para cada produto de interesse comercial identificado. A primeira metodologia buscou constatar a importância do ponto de vista econômico dos produtos exportados e importados por meio do porto de Santos, que representavam cerca de $60 \%$ do valor movimentado nesse porto. $\mathrm{O}$ passo seguinte foi determinar o destino ou origem, conforme o caso, de cada um desses produtos, por município e por unidade da federação. Dessa forma, essa metodologia permitiu uma definição preliminar da área de influência do porto. O estudo propôs o valor de cinco milhões de dólares como o valor mínimo de cada unidade da federação para ser considerado como pertencente à área de influência do porto de Santos. A aplicação desse critério resultou numa área de influência do porto abrangendo 16 estados da federação.

Em uma segunda proposta, diante da deficiência da anterior que considerava somente valores absolutos como critério de definição da zona de influência, Campos Neto e Santos (2005) incorporaram todos os produtos exportados e importados pelo porto de Santos, e as exportações e as importações por município, o que permitiu a agregação por estado do País. Somando os resultados, por estado, das exportações e das importações, foram gerados os valores, em dólares, do comércio internacional de cada estado. Em seguida, foram gerados os dados de participação do porto de Santos no comércio internacional de cada estado. Definiu-se que, caso $10 \%$ do comércio internacional de cada estado utilizasse o porto de Santos, isso demonstraria que o porto tem impacto sobre a economia do referido estado. Por essa metodologia foram considerados hinterland do porto de Santos oito estados brasileiros, a saber: São Paulo, Goiás, Mato Grosso, Tocantins, Mato Grosso do Sul, Minas Gerais, Rondônia e Distrito Federal.

A terceira proposta metodológica, denominada por Campos Neto e Santos (2005) como uma metodologia híbrida, considera não apenas a importância do porto na economia dos estados, mas, também, a relevância em termos de valor monetário na balança comercial movimentada por Santos. Nesse caso, o 
critério de corte englobou as unidades da federação que movimentaram, pelo referido porto, valores iguais ou superiores a US\$ 100 milhões no ano em análise. Dentro da área de interseção dos dois critérios anteriores foram identificados cinco estados: São Paulo, Minas Gerais, Goiás, Mato Grosso e Mato Grosso do Sul. Esses estados foram classificados como a hinterland primária de Santos. O estudo conceituou ainda a hinterland secundária do porto, formada por estados que movimentaram por meio de Santos valores superiores também a US\$ 100 milhões, mas que não contemplavam o critério anterior, isto é, de participação do porto de Santos no comércio internacional do estado superior a 10\%. Esses estados foram: Paraná, Rio de Janeiro, Rio Grande do Sul, Espírito Santo e Bahia.

\section{a) Análise crítica}

Como avaliação crítica, pode-se dizer que a metodologia proposta por McCalla (1999) apresenta semelhança com a proposta por Morgan em 1948 na medida em que ambas utilizam dados de movimentação de carga para a delimitação das zonas de influência portuária. No entanto, McCalla não considera a quantidade movimentada como fator primordial na definição de qual região integra a hinterland do porto. A metodologia proposta pode ser considerada um avanço em relação à de Morgan, quando o autor evidencia a necessidade de se analisar a participação no mercado desses portos, tanto em terra, como em relação a seu foreland.

Por outro lado, a primeira proposta metodológica desenvolvida por Campos Neto e Santos (2005) adota como parâmetro delimitador o valor absoluto das mercadorias. Já a segunda proposta considera a importância da movimentação do porto para o comércio internacional da região de origem/destino das mercadorias. A terceira proposta desses autores consiste na adoção dos dois parâmetros apresentados nas duas primeiras propostas, com o objetivo de inserir na zona de influência uma região importante para o porto em termos comerciais, mas também garantir que esse porto seja importante em termos relativos para o comércio internacional de determinada região.

\subsection{Metodologias para definição da hinterland potencial de um porto}

Existe outro conjunto de metodologias que visa essencialmente realizar uma análise prospectiva do mercado potencial de um porto, ou seja, calcula a delimitação ideal de sua zona de influência utilizando variáveis técnicas, tanto econômicas, como políticas e sociais. Seus resultados indicam a hinterland potencial de um porto ou terminal portuário, em que a área geográfica identificada pode não ser a mesma daquela de sua atuação.

van Klink e Winden (1998) propõem uma metodologia para delimitação da zona de influência potencial de um porto baseada nos custos monetários de transporte. Uma região geográfica será hinterland de um porto se os custos de transporte para esse porto forem menores do que para qualquer outro porto. Caso os custos de transporte entre essa região e dois ou mais portos sejam iguais, essa seria uma região de múltipla influência dos portos, uma vez que poderia movimentar suas cargas por qualquer um dos portos.

Um trabalho de consultoria realizado por uma empresa multinacional envolvida com a captação de cargas de um novo terminal portuário especializado na movimentação de contêineres na região sudeste do Brasil (Estado de São Paulo), inspirado no trabalho de van Klink e Winden (1998), propôs uma metodologia com quatro passos: i) identificados os principais clientes dos portos mais próximos num raio de $500 \mathrm{~km}$ ao novo terminal com os municípios de origem/ destino dos contêineres movimentados por esses portos; ii) orçados os custos de transporte entre os portos e os municípios de origem/destino das cargas e também entre as origens/destinos identificadas e o novo terminal; iii) comparados os custos de transporte para identificação das localidades onde os custos até o novo terminal fossem mais competitivos, então marcadas como potenciais mercados do terminal, enquanto que as localidades com custos semelhantes foram identificadas como áreas de concorrência e aquelas com custos maiores foram descartadas; e iv) a partir dessa identificação, houve um planejamento comercial para a atração de cargas para o novo porto.

Em outro trabalho da mesma natureza, a Secretaria de Infraestrutura do Governo do Estado da Bahia desenvolveu um estudo chamado Programa Estadual de Logística de Transportes: caminhos para o desenvolvimento - PELTBAHIA, publicado em Secretaria de Infra-Estrutura do Governo do Estado da Bahia (2004) em que, ao analisar o impacto de alternativas logísticas em custos de transporte no estado, utiliza uma metodologia para identificar a área de influência dos portos do estado. O impacto das alternativas logísticas foi analisado preliminarmente com base na comparação dos custos de transportes na situação atual e na situação hipotética de aporte de alternativas (tais como a utilização da hidrovia do São Francisco, melhorias na ferrovia existente, dentre outras). A área de influência de cada porto foi estimada com base no critério do custo mínimo, ou seja, um município integra a área de influência de um porto se o custo de transporte até aquele porto for menor do que para qualquer outro porto. Para ambas as alternativas foram elaborados mapas de isocustos que, quando sobrepostos, mostram a delimitação das áreas de influência dos portos baianos. 


\section{a) Análise crítica}

As metodologias listadas e reportadas na seção 4.2, levam em conta apenas os custos de transporte, e deixam de lado importantes variáveis como a frequência de embarcações, a capacidade operacional do porto e outros custos operacionais, como os de armazenagem e de operação portuária.

\section{Estudo de caso}

O objetivo desta seção é o de ilustrar a importância de se trabalhar com o conceito de hinterlands para um planejamento portuário com vistas à identificação do mercado do porto (ou terminal portuário) e de sua hinterland potencial. Este objetivo é atingido por meio de uma análise de um caso real que consiste na delimitação do mercado de atuação do porto de Rio Grande nas exportações de contêineres dos municípios pertencentes ao Estado do Rio Grande do Sul. São analisados tanto o mercado atual deste porto quanto o seu mercado potencial, além da delimitação de suas hinterlands primária e secundária, por meio da análise da participação desse porto no mercado dos municípios do Estado do Rio Grande do Sul, comparativamente aos demais portos da região sul do País. Nesse sentido será usada a premissa de que as exportações de contêineres de municípios pertencentes ao Estado do Rio Grande do Sul por portos brasileiros que não sejam os portos de Rio Grande, São Francisco do Sul, Itajaí e Paranaguá são irrelevantes. A consistência da premissa é que os citados portos são os mais representativos na região sul do Brasil a trabalharem com carga geral conteinerizada.

Para atingir o objetivo foram necessários:

i) Uma combinação de metodologias para delimitação de hinterlands portuárias para permitir as duas análises requeridas: identificar o mercado atual do porto de Rio Grande e o seu mercado. As metodologias estudadas foram então adaptadas ao objetivo do estudo e aos dados disponíveis nas base de dados de movimentação de contêineres;

ii) Uma base de dados para a região sul do Centro Nacional de Navegação Transatlântica (CNNT) com a movimentação de contêineres do porto estudado e de seus concorrentes, que permitiu identificar o município de origem da carga; e

iii) Uma base gráfica georreferenciada da região estudada, obtida junto ao Instituto Brasileiro de Geografia e Estatística (2005), para aplicação no programa computacional de Sistemas de Informação Geográfica (SIG) ArcView .

$\mathrm{O}$ estudo de caso relatado a seguir está subdividido em quatro etapas distintas. A primeira refere-se ao levantamento das cargas exportadas em contêineres pelos municípios gaúchos enquanto que a segunda refere-se à identificação do mercado do porto de Rio Grande, por meio da análise das quantidades movimentadas, conforme preconizado por Morgen em 1948.

$\mathrm{Na}$ terceira etapa, é identificado o market share do porto de Rio Grande, usando como base a metodologia de McCalla (1999), estabelecendo-se as hinterlands primária e secundária do porto em função da participação relativa de mercado desse porto nos municípios gaúchos.

Para a quarta etapa, que corresponde à identificação da hinterland potencial do Porto de Rio Grande, optou-se pela elaboração de uma metodologia própria que fosse capaz de identificar os municípios potencialmente importantes em termos de atração de cargas, sem, contudo, haver a necessidade de cálculo de fretes e demais custos, dados estes não disponíveis, mas usando a utilização dos dados reais de movimentação dos municípios e do porto, para confrontação e delimitação dos municípios a serem alvo de uma ação comercial mais intensa.

\subsection{Exportação de contêineres dos municípios gaúchos pelo porto de Rio Grande}

Buscou-se primeiramente verificar a exportação de contêineres, via um ou mais dos quatros terminais de contêineres dos portos da região sul do Brasil (Rio Grande, São Francisco do Sul, Itajaí e Paranaguá), com origem em municípios pertencentes ao Estado do Rio Grande do Sul. Essa etapa utiliza a metodologia proposta por Morgan. Neste sentido foi consultado o banco de dados da CNNT (CENTRO NACIONAL DE NAVEGAÇÃO TRANSATLÂNTICA/DATAMAR, 2006) para verificar a movimentação de contêineres no sentido exportação, com origem em municípios do estados, via os quatro portos da região sul para o ano de 2003. O ano analisado não é relevante para a presente pesquisa, visto que o objetivo maior é ilustrar a importância do estudo de delimitações de hinterlands e não a problemática atual do terminal em si. As variáveis consultadas e separadas foram:

- Sentido do tráfego: exportação;

- Nome do município de origem, localizado no Estado do Rio Grande do Sul das cargas destinadas a cada um dos quatro portos da região sul;

- Porto (terminal) de destino: Rio Grande, São Francisco do Sul, Itajaí ou Paranaguá; e

- Quantidade total movimentada, medida em capacidade de Twenty Equivalent Unit (TEU).

A partir dos dados obtidos na consulta ao banco de dados, os municípios foram listados em ordem 
decrescente de movimentação e hierarquizados em três categorias, usando-se a classificação ABC, conforme dados contidos na Tabela 1.

Os municípios foram listados em ordem decrescente de movimentação (exportação de contêineres). Aqueles com maior movimentação individual na lista e que somados representam 70\% da movimentação total de contêineres via um ou mais dos portos da região sul do país foram classificados como Municípios com Grande Movimentação. No ano de 2003 este valor foi de 4.961 TEUs. Os municípios com as menores movimentações individuais e que somados representam $10 \%$ da movimentação total de contêineres da região sul foram classificados como Municípios com Pequena Movimentação. Estes foram os municípios que estavam listados no final da lista e que exportaram em 2003 menos de 640 TEUs. Os demais municípios, com movimentações individuais intermediárias, não listados entre as duas outras categorias, que representam acumuladamente $20 \%$ da movimentação total da região sul foram classificados como Municípios com Média Movimentação.

O número de municípios gaúchos que movimentou contêineres em 2003 por um ou mais dos quatro portos da região sul do Brasil foi de 135, totalizando um movimento de exportação de 137.388 TEUs. A Tabela 2 apresenta esse número descriminado por porto e com o respectivo percentual.

Desses 135 municípios, dez podem ser classificados como de grande movimentação e somente dez como de média movimentação. Os municípios classificados como de grande movimentação foram: Porto Alegre (20.011 TEUs), Montenegro (15.594 TEUs), Triunfo (11.105 TEUs), Rio Grande (10.708 TEUs), Vera Cruz (9.274 TEUs), Santa Cruz do Sul (7.336 TEUs), Venâncio Aires (6.481 TEUs), Caxias do Sul (5.019

Tabela 1. Hierarquização dos municípios exportadores gaúchos.

\begin{tabular}{lr}
\hline \multicolumn{1}{c}{ Classificação } & Volume em TEUs \\
\hline Grande movimentação & $>4.961$ TEUs \\
Média movimentação & 641-4.960 TEUs \\
Pequena movimentação & $1-640$ TEUs \\
\hline
\end{tabular}

Tabela 2. Exportação de contêineres do Estado do Rio Grande do Sul pelos portos (terminais de contêineres) da região sul do país. Fonte: CNNT/Datamar (CENTRO NACIONAL DE NAVEGAÇÃO TRANSATLÂNTICA, 2006).

\begin{tabular}{lrr}
\hline \multicolumn{1}{c}{ Porto } & \multicolumn{2}{c}{$\mathbf{N}^{\mathbf{0}}$ em TEUs } \\
\hline Rio Grande & 114.479 & $83,3 \%$ \\
São Francisco do Sul & 6.806 & $5,0 \%$ \\
Itajaí & 14.713 & $10,7 \%$ \\
Paranaguá & 1.390 & $1,0 \%$ \\
Total & 137.388 & $100 \%$ \\
\hline
\end{tabular}

TEUs), Canoas (4.992 TEUs) e Novo Hamburgo (4.961 TEUs), totalizando 95.481 TEUs.

Uma vez identificados e classificados os municípios do Estado do Rio Grande do Sul que movimentaram carga conteinerizada por um ou mais dos quatro portos da região sul, foi necessário compatibilizar os dados obtidos na base de dados da CNNT com a base de dados georreferenciada obtida junto ao IBGE. A necessidade de compatibilização se deve ao fato da base de dados da CNNT não possuir o geocódigo do município e, também, à impossibilidade de junção das duas bases por meio do uso dos nomes dos municípios dadas as diferentes grafias desses nomes nas duas bases disponíveis. Uma vez compatibilizadas as bases, foi possível incorporar as consultas e classificações ao programa computacional ArcView de forma a se visualizar graficamente os municípios do Estado do Rio Grande do Sul que movimentaram contêineres por um ou mais dos quatro portos da região sul do País, de acordo com sua respectiva classificação ABC. A Figura 1 expõe os resultados obtidos apresentados no SIG (ArcView) para o ano de 2003.

\subsection{Mercado do porto do Rio Grande}

O próximo passo foi identificar os municípios gaúchos que utilizaram o porto de Rio Grande nas exportações de contêineres, de forma a delimitar o mercado de atuação deste porto, usando a metodologia proposta por Morgan e a mesma hierarquização e classificação de municípios de grande, média e pequena movimentação apresentada na Tabela 1.

A análise realizada mostra que dos 135 municípios do Estado do Rio Grande do Sul que utilizaram os portos da região sul do país em 2003 para exportação de contêineres, apenas 7 não utilizaram o Porto de Rio Grande.

Os principais municípios gaúchos que movimentaram contêineres pelo porto de Rio Grande, classificados como de grande movimentação foram: Montenegro (12.461 TEUs), Triunfo (11.097 TEUs), Rio Grande (10.676 TEUs), Porto Alegre (10.651 TEUs), Vera Cruz (9.274 TEUs), Santa Cruz do Sul (7.268 TEUs) e Venâncio Aires (6.465 TEUs). Outros dezoito municípios foram classificados como de média movimentação, como apresentado na Figura 2.

\subsection{Hinterland do porto de Rio Grande segundo seu market share}

Esta etapa tem como objetivo delimitar a zona de influência do Porto de Rio Grande, por meio da análise de seu market share. A principal diferença entre este estudo e as demais etapas realizadas é que as primeiras etapas se basearam na identificação do mercado do porto pela análise das quantidades de 

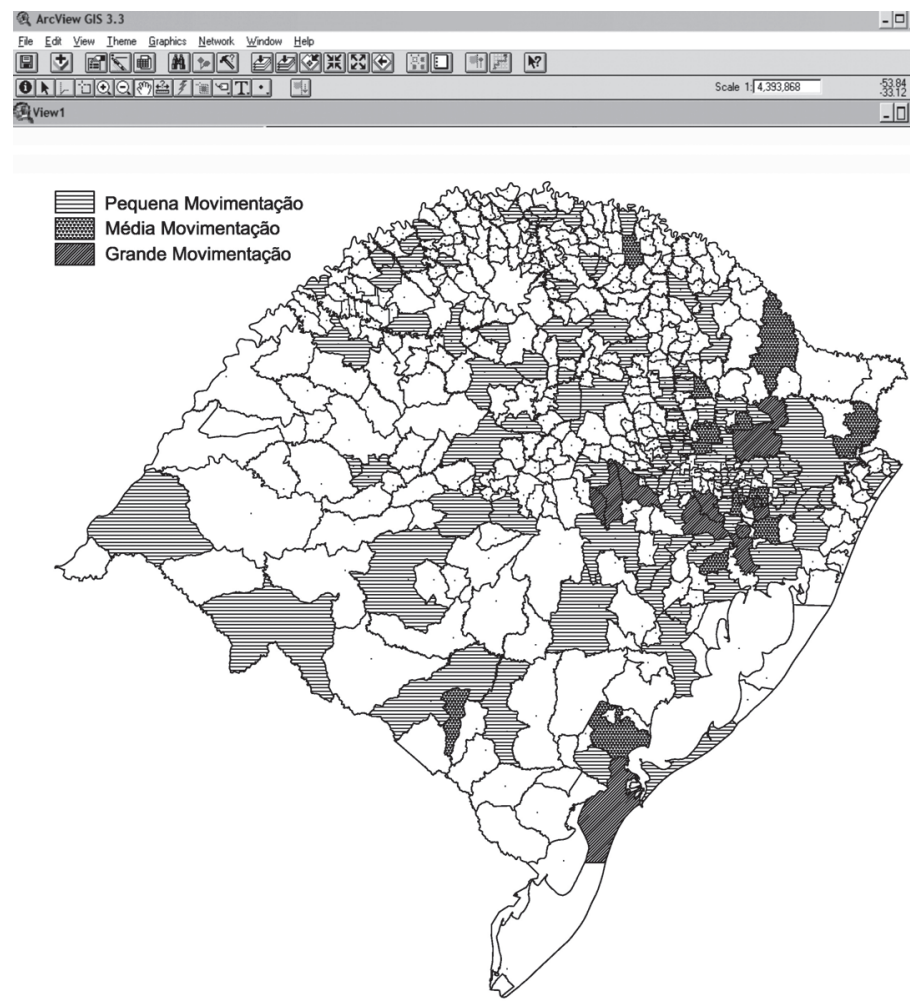

Figura 1. Movimentação de contêineres dos municípios gaúchos via portos da região sul.

contêineres movimentadas, enquanto a etapa atual analisa a hinterland do porto pelo estudo de seu market share em relação aos demais portos analisados da região sul.

Para a elaboração desta etapa foi utilizada a metodologia proposta por McCalla (1999), usando os dados de movimentação de contêineres dos municípios gaúchos sendo calculado o market share do porto de Rio Grande para cada um dos municípios. Esse levantamento permitiu identificar georreferenciadamente os municípios que compõem a hinterland do porto e identificar as hinterlands primária e secundária, seguindo a classificação dada em Degrassi (2001), pois se pretendeu hierarquizar a importância de determinada região para a movimentação de cargas conteinerizadas no porto de Rio Grande, com o objetivo de permitir, em primeira instância, uma análise mercadológica focada nas regiões que geram maiores quantidades movimentadas pelo porto, com base nos seguintes critérios:

- Se o Porto de Rio Grande movimenta $70 \%$ ou mais do total de contêineres movimentados pelo município gaúcho nos portos da região sul, esse município é considerado hinterland primária do Porto;
- Se o Porto de Rio Grande movimenta entre $40 \%$ e $70 \%$ do total de contêineres movimentados pelo município gaúcho nos portos da região sul, esse município é hinterland secundária do Porto, podendo ser entendida também como área de múltipla influência, conforme descrito em Slack (1993) e Kesic, Komadina e Cisic (1998).

Realizadas todas as classificações e identificações dos municípios componentes das hinterlands primária e secundária de Rio Grande, além da compatibilização das bases de dados, essas zonas de influência foram plotadas no ArcView de forma georreferenciada, como apresentado na Figura 3.

A grande maioria dos municípios gaúchos que movimentou cargas pelo porto de Rio Grande em 2003 caracterizava-se como hinterland primária do porto, havendo somente 16 municípios definidos como hinterland secundária. No entanto, dentre esses 16 municípios consta Porto Alegre que, apesar de movimentar grande parte de suas cargas pelo porto de Rio Grande, ainda apresenta elevada movimentação por outros portos da região sul.

A delimitação da hinterland do porto de Rio Grande por meio do estudo de market share nos municípios pertencentes ao Estado do Rio Grande do Sul evidencia a posição consolidada do porto em relação a este mercado. Conforme mostrado na Tabela 2, o porto 


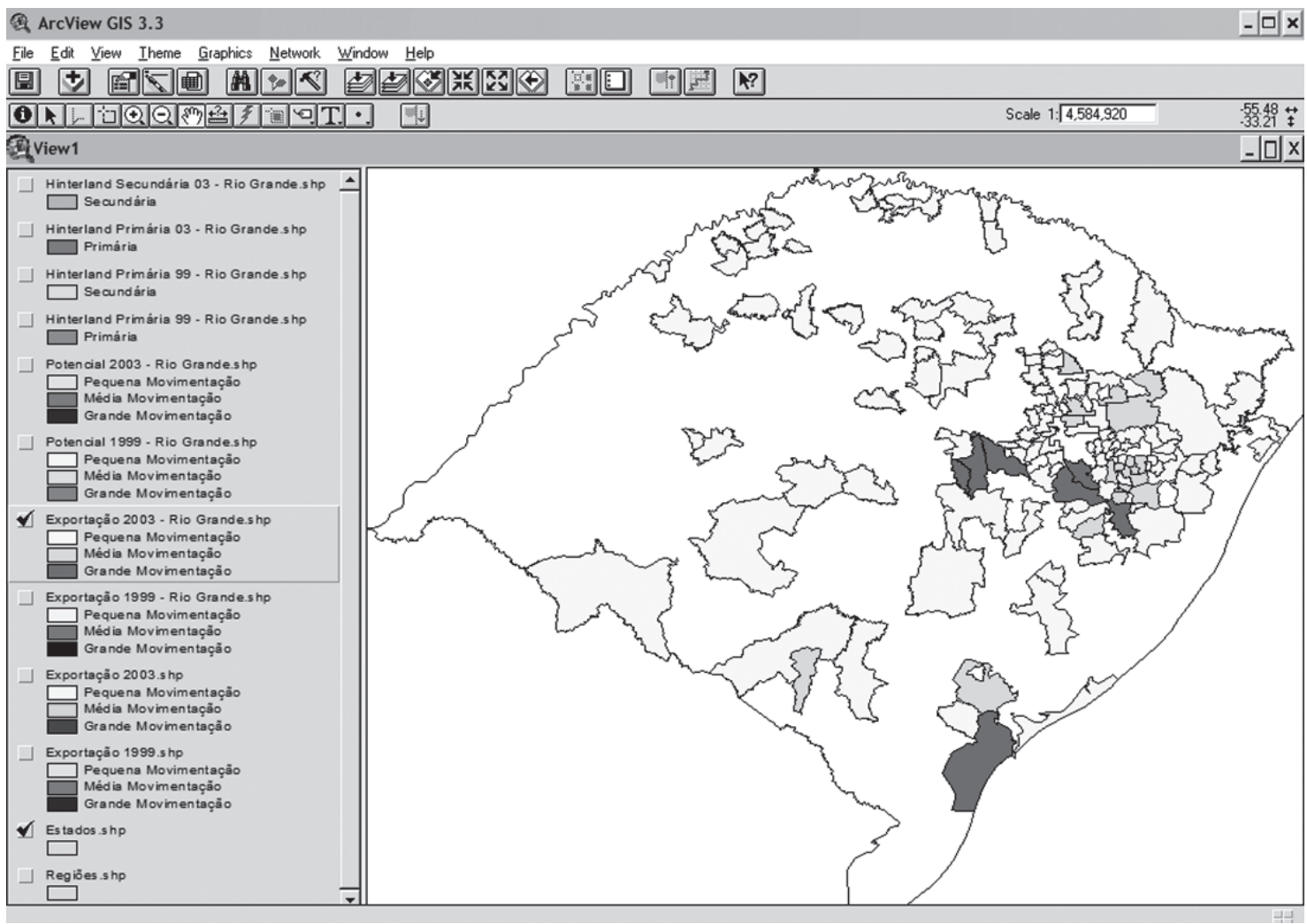

Figura 2. Municípios gaúchos com movimentação de contêineres pelo porto de Rio Grande.

movimentou mais de $80 \%$ dos contêineres exportados pelos municípios gaúchos. Assim, o estudo realizado nesta etapa confirma este diagnóstico, já que a análise de cada município isoladamente mostra que a maioria dos municípios gaúchos compõe a zona de influência primária do porto, exportando mais de $70 \%$ de seus contêineres via Rio Grande.

\subsection{Hinterland potencial do porto de Rio Grande}

O objetivo desta etapa é verificar quais municípios gaúchos se caracterizam como mercado potencial do porto de Rio Grande, isto é, quais municípios possuem contêineres ainda não movimentados via este Porto e sua importância comercial para o Porto.

Uma vez que as metodologias estudadas para a delimitação da hinterland potencial de um porto utilizam como variável principal de análise o custo de transporte entre o local de origem da carga e o porto, e como esta variável não está disponível nas bases de dados obtidas, foi elaborada uma metodologia própria para a realização desta etapa do estudo.

Esta etapa se caracteriza como uma análise complementar à realizada nas Etapas 1 e 2, dado que, para se encontrar os municípios com movimentação potencial para o porto de Rio Grande, foram analisadas as movimentações totais de contêineres dos municípios gaúchos e também a carga destes municípios já absorvida pelo porto de Rio Grande. Com base nessas informações, pôde-se obter o mercado potencial do porto no Estado do Rio Grande do Sul. A operação realizada para a definição da movimentação potencial de contêineres do Porto de Rio Grande é apresentada pela Equação (1), ou Equação de Movimentação Potencial:

$$
M \mathrm{Pot}_{n}=\mathrm{MGe}_{n}-M R G_{n}
$$

em que:

$M P o t_{n}$ - é a movimentação potencial de contêineres do município n para o porto de Rio Grande;

$M G e_{n}$ - é a movimentação de contêineres do município $\mathbf{n}$ via um ou mais dos quatro portos da região sul; e

$M R G_{n}$ - é a movimentação de contêineres do município $\mathbf{n}$ via o porto de Rio Grande.

Essa operação permite visualizar graficamente quais os municípios localizados no Estado do Rio Grande do Sul que movimentam contêineres pelos quatro portos da região sul do país e que se caracterizam como mercado potencial do porto de Rio Grande. 

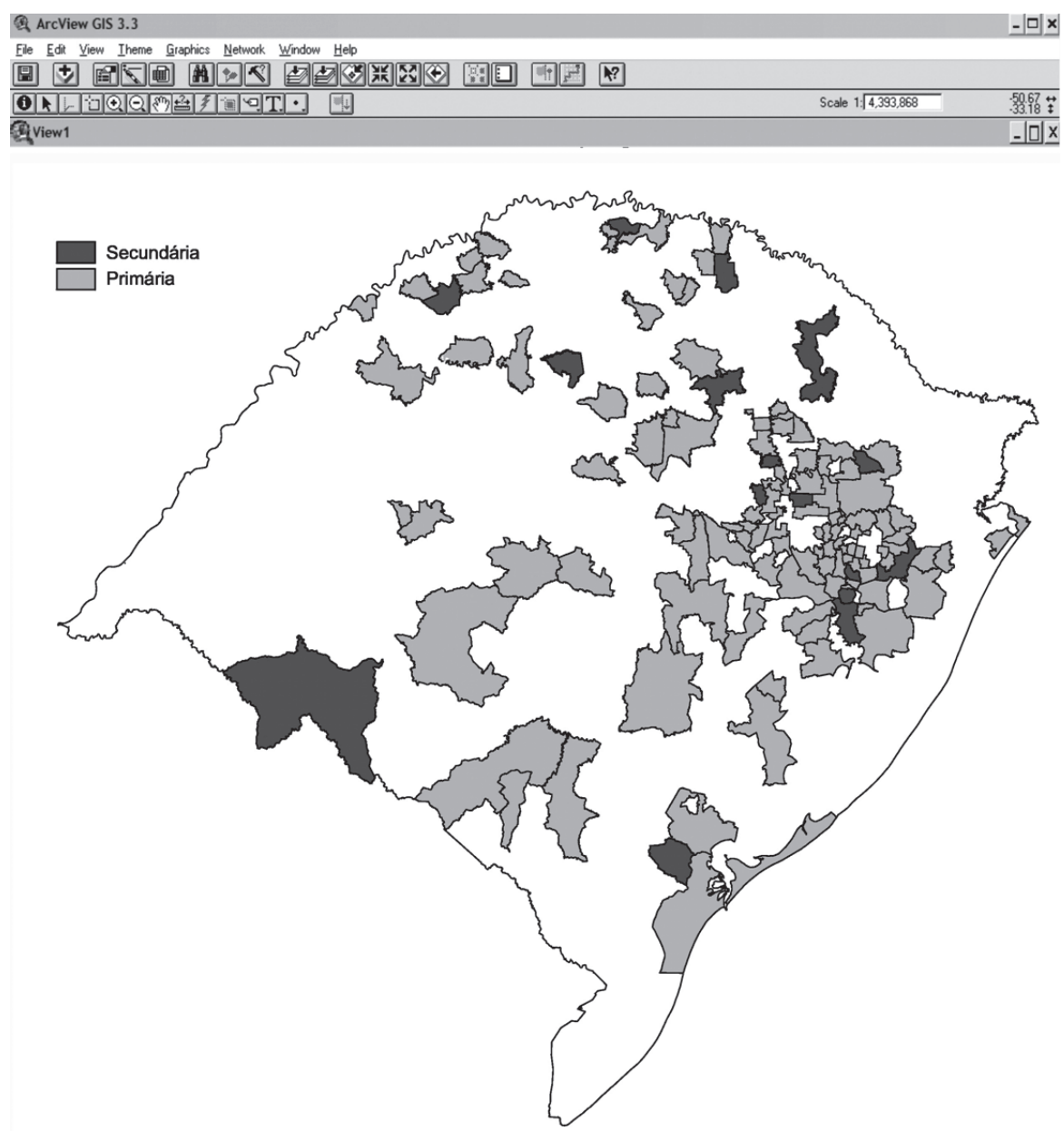

Figura 3. Hinterlands primária e secundária do porto de Rio Grande.

Uma vez identificados os municípios com carga potencial para o Porto de Rio Grande, estes foram hierarquizados e classificados em municípios de grande, médio e pequeno potencial, com base no mesmo critério da Tabela 1.

Uma vez identificados e classificados os municípios caracterizados como mercado potencial do porto de Rio Grande, esses dados foram incorporados ao programa computacional ArcView, o que permitiu a visualização em mapas georreferenciados do mercado potencial do porto. A Figura 4 caracteriza os municípios como mercados potenciais do Porto de Rio Grande para o ano de 2003.

O número de municípios com carga potencial para Rio Grande é 70. Dentre esses, a análise da hinterland potencial do porto de Rio Grande mostra que o município ao qual deve ser dada maior atenção comercial no estado é o de Porto Alegre, uma vez que, apesar de já movimentar cargas por Rio Grande, oferece ainda um grande potencial, sendo o município de maior potencial do estado, com uma quantidade possível de atração adicional de 9.360 TEUs. Suas cargas por outros portos da região sul do país eram, 5.877 TEUs para Itajaí, 3.380 TEUs para São Francisco do Sul e 102 TEUs para Paranaguá.

Os municípios de Montenegro (3.133 TEUs), Canoas (2.035 TEUs), Garibaldi (1.483 TEUs), Caxias do Sul (1.272 TEUs), Vacaria (797 TEUs), Cambará do Sul (758 TEUs) e Novo Hamburgo (721 TEUs) constituem os municípios de médio potencial do estado, enquanto os demais 62 municípios identificados pela metodologia aplicada são de pequeno potencial para o porto.

Ainda, devido à elevada participação do Porto de Rio Grande nas exportações de contêineres dos municípios gaúchos, o potencial de atração de novas cargas para este porto a partir desses municípios é bastante restrito. Contudo, deve focar especial atenção nos municípios de grande e médio potenciais e em municípios de estados vizinhos. 

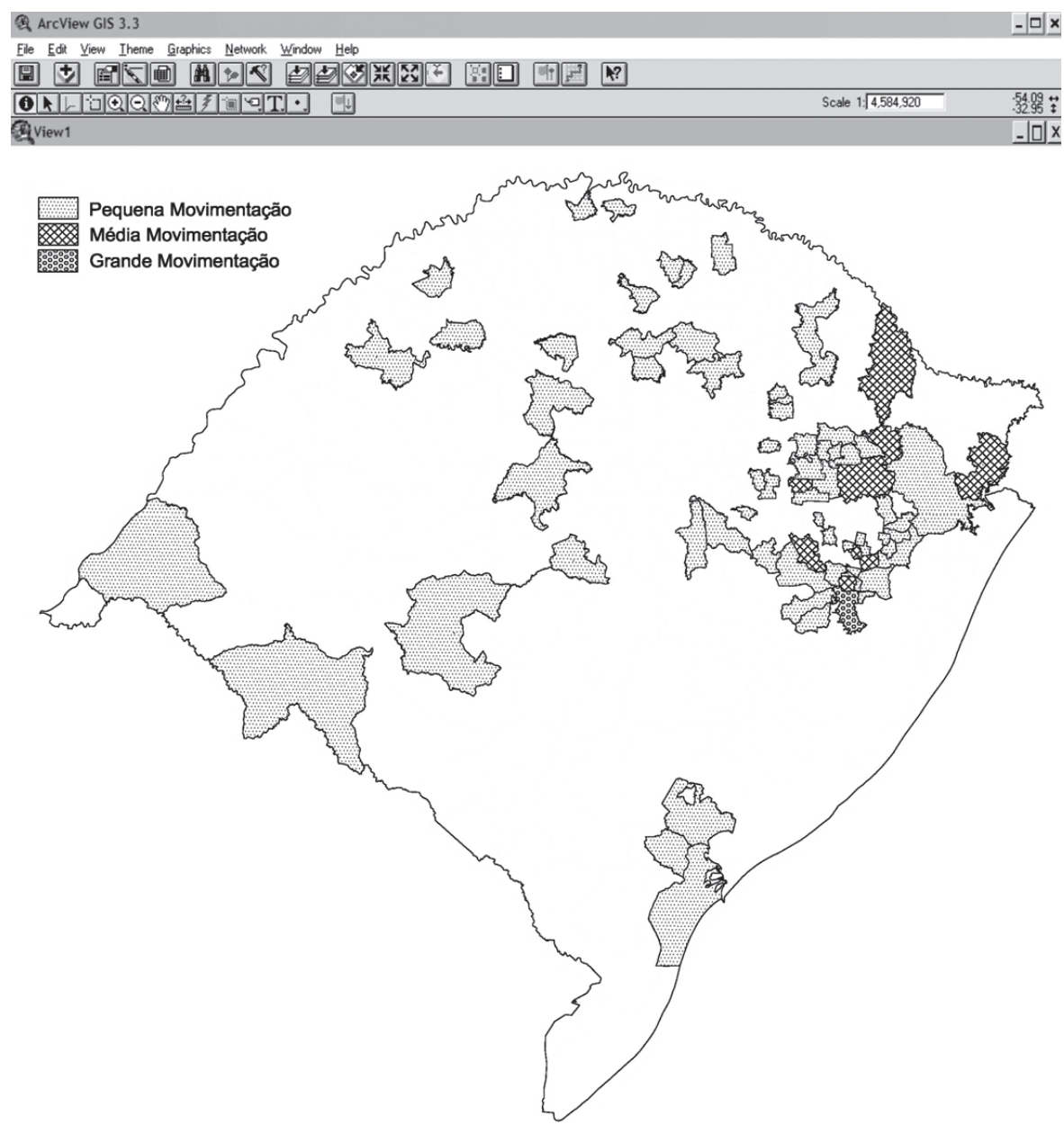

Figura 4. Municípios gaúchos com potencial de movimentação para o porto de Rio Grande.

\section{Conclusões}

O ambiente competitivo em que os portos estão contextualizados exige o correto planejamento do desenvolvimento portuário de forma a oferecer infraestrutura e serviços adequados à atual realidade. Essa realidade é muito afetada pela utilização dos contêineres como ferramenta de transporte e pelo desenvolvimento de redes de transporte intermodal. Esses fatos, associados ao crescente poder de mercado das empresas de navegação mundiais e à logística de transporte dos contêineres, marcada pela utilização de megacarriers que aportam em poucos portos hub, concentradores de cargas, alimentados por linhas feeder de menor porte, diminuíram sensivelmente a posição do porto como operador monopolista de cargas de uma determinada região. Neste contexto, uma importante ferramenta de planejamento estratégico de um porto consiste na identificação de sua zona de influência, processo este que inclui igualmente a avaliação da zona de influência análoga dos seus principais concorrentes portuários. Apesar de inúmeras definições, de forma geral, as hinterlands podem ser consideradas como o mercado efetivo de um porto ou o espaço geoeconômico em que este vende serviços e interage com seus clientes. Dessa forma, a hinterland é tratada como algo dinâmico e mutável, que pode ser disputada por diversos portos na medida em que consigam ofertar seus serviços de maneira competitiva no mercado.

$\mathrm{O}$ presente estudo das metodologias para a delimitação de hinterlands portuárias mostra que, apesar da discussão na literatura especializada acerca deste tema ser ainda escassa, portos e empresas de consultoria do ramo vêm utilizando este conceito e formando metodologias próprias para sua delimitação e conhecimento, o que permite às autoridades e terminais a elaboração de planos de desenvolvimento portuários. Os autores deste artigo identificaram metodologias para esta delimitação, que foram classificadas por eles em metodologias que visam a identificação do mercado de um porto, e metodologias que visam delimitar a hinterland potencial de um porto. 
O caso estudado do Terminal de Contêineres do Porto de Rio Grande analisou, para o Estado do Rio Grande do Sul, o mercado de atuação deste terminal por meio da combinação de duas metodologias levantadas na bibliografia (McCALLA, 1999; e MORGAN, apud DEGRASSI, 2001) e de uma proposta elaborada pelos autores deste artigo. Neste sentido, há uma contribuição adicional dos autores ao se combinar as metodologias, o que possibilitou a identificação do mercado do terminal e de sua potencialidade, para adequá-las à realidade estudada, desenvolvendo-se ainda uma nova metodologia, que permitiu atingir o objetivo do estudo de caso, ressaltando a importância do conceito de hinterland para o planejamento portuário. As delimitações das hinterlands foram visualizadas em mapas georreferenciados, elaborados por meio da utilização do programa computacional ArcView. Com base nesse caso, observou-se que as áreas de múltipla influência ainda não são uma realidade, tendo o terminal o domínio do mercado de exportação de contêineres do Estado do Rio Grande do Sul, com market share superior a $80 \%$. Provavelmente, a análise análoga de portos como os de Itajaí e São Francisco do Sul e, até mesmo o de Santos, poderá revelar resultados diversos dos encontrados em Rio Grande e oferecer diretrizes próprias para seus planejamentos e desenvolvimentos competitivos, mostrando a importância do estudo das áreas de múltipla influência para esses portos. A determinação da hinterland de um terminal portuário como ferramenta de análise de seu mercado mostrou-se importante no sentido de identificar sua área de atuação e seu potencial de expansão e atração de cargas, possibilitando o planejamento para enfrentar a competição pelos novos mercados identificados e, principalmente, para a manutenção dos clientes já conquistados, como forma de desenvolvimento sustentável do terminal.

\section{Referências}

BICHOU, K.; GRAY, R. A critical review of conventional terminology for classifying seaports. Transportation Research, p. 75-92, 2005.

BIRD, J. H. Seaports and seaport terminals. Londres: Hutchinson \& Co., 1971.

CAMPOS NETO, C. A. S.; SANTOS, M. B. Atração de cargas para o porto de Santos: perspectiva e crescimento sustentável. Brasília: IPEA, 2005.

CENTRO NACIONAL DE NAVEGAÇÃO TRANSATLÂNTICA - CNNT/DATAMAR. Banco de dados movimentação de contêineres da região sul do Brasil. 2006.

DEGRASSI, S. The seaport network Hamburg. 2001. Tese (Doutorado)-Universidade de Hamburgo, Hamburgo, 2001.
ESRI. The Geographic Information System for Everyone. Redlands, Califórnia: Enviromental Systems Research Institute, 1996.

HAEZENDONCK, E.; NOTTEBOOM, T. The competitive advantage of seaports. In: HUYBRECHTS, M. et al. (Ed.). Port competitiveness, an economic and legal analysis of the factors determining the competitiveness of seaports. De Boeck: Antwerp, 2002. p. 67-87.

HAYUTH, Y. Inter-modal transportation and the hinterland concept. In: TESG. Tijdschrift voor Economische en Sociale Geografie. 1982. p. 13-21.

HOYLE, B. Global and local forces in developing countries. Journal for Maritime Research, 2000.

INSTITUTO BRASILEIRO DE GEOGRAFIA E ESTATÍSTICA - IBGE. Base de dados municipal. Rio de Janeiro, 2005.

KESIC, B.; KOMADINA, P.; CISIC, D. Towards the unified theory of the port gravitational areas introducing information centrality factors. Croácia: Universidade de Rijeka, 1998.

KONINGS, R. Opportunities to improve container barge handling in the port of Rotterdam from a transport network perspective. Journal of Transport Geography, v. 15, p. 443-454, 2007.

LACERDA, S. M. Navegação e portos no transporte de contêineres. Revista do BNDES, v. 11, n. 22, p. 215-243, 2004.

LEE, S-W.; SONG, D-W.; DUCRUET, C. A tale of Asia's world ports: the spatial evolution in global hub port cities. Geoforum, v. 39, p. 372-385, 2008.

McCALLA, R. J. Container transshipment at Kingston Jamaica. Journal of Transport Geography, v. 16, p. 182-190, 2008.

McCALLA, R. J. Global change, local pain: intermodal seaport terminals and their service areas. Journal of Transport Geography, v. 7, p. 247-254, 1999.

NOTTEBOOM, T.; RODRIGUE, J. P. Re-assessing port-hinterland relationships in the context of global commodity chains. In: WANG, J. et al. (Ed.). Ports, cities, and global supply chain. Ashgate, 2007. p. 51-66.

PETTIT, S. J.; BERESFORD, A. K. C. Port development: from gateways to logistics hubs. Maritime Policy and Management, v. 36, n. 3, p. 253-267, 2009.

RODRIGUE, J. P.; NOTTEBOOM, T. Foreland-based regionalization: Integrating intermediate hubs with port hinterlands. Research in Transportation Economics, v. 27, p. 19-29, 2010.

ROSO, V.; WOXENIUS, J.; LUMSDEN, K. The The dry port concept: connecting container seaports with the hinterland. Journal of Transport Geography, v. 17, p. 338-345, 2009.

SECRETARIA DE INFRA-ESTRUTURA DO GOVERNO DO ESTADO DA BAHIA -SEINFRA. Programa estadual de logística de transportes: caminhos para o desenvolvimento. Salvador, 2004.

SLACK, B. Pawns in the game: ports in a global transportation system. Growth and Change, v. 24, p. 379-388, 1993.

SONG, D. W. Port co-operation in concept and practice. Maritime Policy and Management, v. 30, n. 1, p. 29-44, 2003. 
STARR, J. The mid-Atlantic load centre: Baltimore or Hampton roads. Maritime Policy and Management, v. 21, n. 3, p. 219-227, 1994.

TAKEL, R. E. Port and Hinterland Relationships. UNCTAD, Manual on Port Management, v. 2, p. 67-73, 1976.

TAN, T-Y. Port cities and hinterlands: a comparative study of Singapore and Calcutta. Political Geography, v. 26, n. 7, p. 851-865, 2007.

UBOGU, A. E., ARIYO, J. A.; MAMMAN, M. Porthinterland trucking constraints in Nigeria. Journal of Transport Geography, in press. doi:10.1016/j. jtrangeo.2009.09.001.

UNITED NATIONS CONFERENCE ON TRADE AND DEVELOPMENT - UNCTAD. Commercial development of regional ports as logistics centres. New York, 2002. van KLINK, H. A.; van den BERG, G. C. Gateways and intermodalism. Journal of Transport Geography, v. 6, p. 1-9, 1998.

van KLINK, H. A.; WINDEN, W. Towards a new hinterland orientation for Rotterdam: the entrepreneurial port. In: CONGRESS OF THE EUROPEAN REGIONAL SCIENCE ASSOCIATION, 38., 1998.

VELASCO, L. O. M.; LIMA, E. T. As novas empresas de navegação determinam a evolução dos portos. Revista BNDES, n. 11, 1999.

YAP, W. Y.; LAM, J. S. L. Competition dynamics between container ports in East Asia. Transportation Research Part A: Policy and Practice, v. 40, n. 1, p. 35-51, 2006. YEO, G-T; ROE, M.; DINWOODIE, J. Evaluating the competitiveness of container ports in Korea and China. Transportation Research Part A: Policy and Practice, v. 42, n. 6, p. 910-921, 2008. 